\title{
De LA MILPA AL FIELD: LA EXPERIENCIA MIGRATORIA DE JÓVENES ZAPATISTAS EN LOS CAMPOS DE CULTIVO CALIFORNIANOS
}

\author{
Alejandra Aquino Moreschi
}

Resumen: En el siguiente artículo analizo, desde una perspectiva etnográfica, la experiencia migratoria de un grupo de jóvenes zapatistas convertidos en jornaleros agrícolas en el valle de California. Estos jóvenes, al incorporarse a ese nicho laboral, se convierten en una fuerza de trabajo cautiva a la que, por diferentes mecanismos, se le impide su movilidad geográfica, profesional y social. Frente al control de su movilidad y ante la imposibilidad de la acción colectiva en los campos, los jóvenes zapatistas optan por la "fuga" hacia otras regiones y otros mercados de trabajo.

Palabras clave: Migración internacional, agricultura, jóvenes, zapatismo, capitalismo.

Enviado a dictamen: 17 de abril de 2012

Aprobación: 20 de abril de 2012

Revisiones: 1

Dra. Alejandra Aquino Moreschi, doctora en sociología por la École des Hautes Études en Sciences Sociales (EHESS), Paris. Actualmente es investigadora en el CIESAS-Pacifico Sur. Temas de especialización: Migración Internacional, Luchas por el reconocimiento, zapatismo. Correo electrónico: alejandra.aquinom@yahoo.com.
Abstract: In the following article I analyze the migratory experience of a group of young zapatists who have turned into agricultural day laborers in the California valley. Who, once incorporated into this labor niche, turn into a captive labor force which through different mechanisms is prevented from its geographical, professional and social mobility. The control of their mobility and the impossibility of collective action in the camps, the young zapatists opt for the "flight" towards other regions and other labor markets.

Keywords: International migration, agriculture, young people, zapatismo, capitalism.

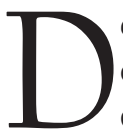
esde el año 2002, jóvenes de diferentes comunidades zapatistas de la parte selvática del municipio de Las Margaritas comenzaron a emigrar a Estados Unidos. Algunos de ellos se encuentran dispersos en los estados del centro y este del país, y otros, se han establecido en el estado de California, particularmente en los condados rurales, donde se encuentran trabajando como jornaleros agrícolas. Su incorporación a la agricultura californiana no es un hecho casual. Anualmente este estado genera alrededor de 24 billones de dólares en utilidades por la venta de sus productos agrícolas ya que nueve de los diez condados más productivos de Estados Unidos 
se encuentran en este estado (California Departament of Food and Agriculture, 2006).

Aunque la agricultura californiana está altamente tecnificada, las cosechas se siguen recogiendo a mano, de ahí que se trate de un tipo de agricultura que siempre ha estado ligada a la sobreexplotación de mano de obra migrante, en gran parte indocumentada (Berlan, 1986). Cada año los trabajadores migrantes cultivan, cosechan y empacan toneladas de uva, fresa, durazno, limón, naranja, lechuga, tomate, brócoli, zanahoria, alcachofa, espárrago, aceituna, nuez, almendra, pistacho y todo tipo de frutas, vegetales y hortalizas. Cultivos que requieren de mucho cuidado para su recolección, así como de mano de obra abundante en ciertos periodos del ciclo agrícola. Gracias al trabajo de los migrantes, Estados Unidos se ubica como el principal productor y exportador de alimentos a escala mundial, y millones de familias estadounidenses tienen asegurado el acceso a los alimentos a menor precio que en otras partes del mundo.

Desde mediados del siglo XX, la fuerza de trabajo de los campos californianos ha sido predominantemente mexicana. ${ }^{1}$ En una primera etapa se trataba de mano de obra proveniente de los estados con mayor tradición migratoria como Guanajuato, Jalisco y Michoacán (Durand y Massey, 2003); siendo desplazada posteriormente por mano de obra indígena originaria del estado de Oaxaca. Sin embargo, desde hace algunos años, han llegado también cientos de trabajadores de Veracruz y finalmente de Chiapas, estos últimos, mayoritariamente indocumentados, sin experiencia previa en la migración trasnacional y muy jóvenes. Como han mostrado algunos autores (Paris, 2008; Holmes, 2006; Nagengast y Kearney, 1990; Zabin, Kearney, Runsten y otros, 1993), el trabajo agrícola en Estados Unidos se estructura siguiendo una jerarquía organizada en función de la pertenencia étnica y la ciudadanía, que sitúa en primer lugar a los ciudadanos estadounidenses blancos, seguidos de los residentes de origen latino, los mexicanos mestizos indocumentados y finalmente los mexicanos indígenas sin papeles, quienes por mucho tiempo fueron mayoritariamente mixtecos de Oaxaca ${ }^{2}$ pero que ahora también son chiapanecos pertenecientes a diferentes municipios, incluidos los municipios autónomos zapatistas.

En el siguiente artículo analizo la experiencia migratoria de un grupo compuesto aproximadamente por 30 jóvenes chiapanecos, zapatistas convertidos en jornaleros agrícolas, cuyas trayectorias migratorias seguí durante 2005 y 2006. Todos son originarios de una comunidad zapatista ubicada en el municipio de las Margaritas, Chiapas. La mayoría emigró por primera vez entre el 2003 y el 2005, y muchos de ellos se establecieron en los condados de Kern, Tulare y San Joaquín, en California. La experiencia migratoria de estos jóvenes me permitirá mostrar cómo, al incorporarse a la agricultura californiana, quedaron convertidos en lo que Moulier-Boutang (1998: 73) ha llamado un "salariat bridée", es decir, una "fuerza de trabajo cautiva" a la que, por diferentes mecanismos — que van de la simple constricción, a diversas formas de disuasión y explotación-, se le impide su movilidad geográfica, profesional y social. Se mostrará también cómo, frente al control de su movilidad y ante la imposibilidad de la acción colectiva en los campos, los migrantes chiapanecos optan por la "fuga" hacia otras regiones y otros mercados de trabajo. Tomar esta experiencia de los migrantes chiapanecos como unidad analítica me permitirá, por un lado, aprehender las subjetividades de estos jóvenes restituyendo así su papel como actores y, por otro, comprender cómo funciona el sistema de producción agrícola en California. En otras palabras, el análisis de la experiencia migratoria será como una ventana para observar algunas de las consecuencias de la globalización y del sistema de producción capitalista sobre la vida cotidiana y las perspectivas futuras de los jóvenes migrantes de Chiapas. $^{3}$ 


\section{El contexto de salida y el perfil de los migrantes}

En gran parte de los municipios del estado de Chiapas la migración internacional hacia Estados Unidos es un fenómeno que ha cobrado gran fuerza en la última década y que está transformando las dinámicas locales (véase Jáuregui y Ávila, 2007; Villafuerte y García, 2006; Pickard, 2006; Rus y Rus, 2008). En la parte selvática del municipio de Las Margaritas la migración comenzó hacia el año $2000 \mathrm{y}$, al igual que en el resto del estado, los migrantes son centralmente hombres de entre $15 \mathrm{y}$ 35 años, aunque predomina el sector que va de 15 a 25 . Estos jóvenes pertenecen a una generación a la que voy a llamar "zapatistas de cuna" ya que se trata de personas que vivieron su niñez y adolescencia en la era post levantamiento, después del primero de enero de 1994.

A esta generación no le tocó conocer cómo fue la vida en la selva antes de la rebelión y el establecimiento de los municipios autónomos. Desde que eran pequeños, la región estuvo bajo la influencia del EZLN, por lo que nunca tuvieron que trabajar bajo las órdenes de un patrón, no trataron jamás con los funcionarios gubernamentales ni tampoco asistieron a las escuelas del gobierno. De hecho, todos ellos estudiaron en las escuelas autónomas zapatistas y se atendieron en las clínicas zapatistas. Para resumir, es una generación que nace "dentro" del zapatismo y que se encuentra bastante politizada.

Algunos investigadores han explicado la migración chiapaneca enfatizando los factores económicoestructurales. Por ejemplo, Villafuerte y García (2006) argumentan que el crecimiento de la migración en Chiapas tiene que ver con la crisis rural en la que se encuentra el estado desde 1988 y sus efectos: el desplome del empleo y la agudización de la desigualdad social provocadas por las políticas neoliberales aplicadas al campo y, finalmente, la caída de los precios del café en 1989 y 1998. La aceleración del fenómeno migratorio también se ha explicado como consecuencia de los desastres ocasionados por el huracán Mitch, en septiembre de 1998, y el huracán Stan, en octubre de 2005, en las zonas del Istmo, la Costa y el Soconusco, ya que dejaron sin hogar a cientos de miles de familias y arrasaron con miles de hectáreas de tierras de cultivo (Castro, 2005). Además de los factores económicos, la migración de los jóvenes tojolabales se encuentra estrechamente relacionada con 16 años de guerra de baja intensidad en contra de las comunidades rebeldes. Durante mucho tiempo las bases zapatistas tuvieron la convicción de que, por medio del diálogo con la sociedad civil y el Estado, podrían ver resueltas sus reivindicaciones en el mediano plazo. Sin embargo, cuando fue evidente que el Estado no estaba dispuesto a cumplir con lo firmado durante las negociaciones de San Andrés, algunos jóvenes zapatistas se desanimaron y comenzaron a seguir el mismo camino que los campesinos de las comunidades no zapatistas habían emprendido años atrás: la migración internacional (Aquino, 2009). No es casualidad que la primera oleada migratoria zapatista en las comunidades estudiadas tuviera lugar en el periodo 2002-2003, en una coyuntura nacional nada esperanzadora, pues los tres poderes del Estado se habían negado a cumplir con los Acuerdos de San Andrés.

La migración a Estados Unidos constituye un desafío central para todos estos jóvenes campesinos quienes, al emigrar, se tendrán que incorporar a nuevos circuitos globales de trabajo bajo un régimen capitalista de "acumulación flexible" (Harvey, 1998), y se enfrentarán a nuevas formas de explotación, precariedad y racismo, así como al hecho de trabajar por primera vez para un patrón.

\section{La entrada a la agricultura californiana}

El segundo día de estar aquí en Estados Unidos pasó un raitero ahí en la pensión en la que estábamos y nos dijo: "Hey muchachos, ino quieren ir a trabajar?". "Pues sí claro, pues para eso venimos" (...) "Pues te voy a llevar en el espárrago porque ayer me hablaron 
y quieren gente, oigan, y icuánto tiempo tienen aquí?". "Acabamos de llegar, tenemos dos días". "No se preocupen por eso, yo los voy a llevar al trabajo (...) aquí no tengan miedo, ni de la policía, ni de nada, aquí ya están en Estados Unidos, ya triunfaron".

Inmediatamente después de haber llegado a California, algunos de los jóvenes zapatistas empezaron a trabajar en un rancho cercano a la ciudad de Arvin. Ante la falta de una red migratoria sólida su entrada al mercado de trabajo se dio por medio de "enganchadores" o amistades fortuitas, es decir, se han apoyado en lo que Granovetter (1999: 42) llama "vínculos débiles", o sea, relaciones interpersonales que se van creando sobre la marcha y que se caracterizan por ser muy recientes, de baja intensidad emocional, y en las que existe poca confianza mutua. El hecho de que se apoyen en estas redes tiene que ver con que, para los migrantes recién llegados, resulta difícil acceder directamente a un empleador pues el sistema de la agricultura californiana está hecho para funcionar mediante diferentes tipos de intermediarios. Además, los nuevos migrantes no hablan inglés, no conocen el funcionamiento del sistema y no tienen los contactos necesarios.

La inserción de los chiapanecos en el mercado de trabajo se da vía los "enganchadores": el último eslabón de este sistema de subcontratación. Casi siempre se trata de otros jornaleros agrícolas que llevan más tiempo en la región y que aprovechan sus contactos con los mayordomos para sacar algunos ingresos extras. Los "enganchadores", además de introducir a los migrantes al mercado de trabajo, les enseñan cómo realizar las diferentes tareas como jornaleros, ya que, aunque muchos de los recién llegados son campesinos, no conocen los cultivos que se trabajan en la región ni están acostumbrados a esta forma de producción.

Si bien los jóvenes zapatistas lograron incorporarse rápidamente al mercado de trabajo gracias a los "enganchadores", lo hicieron bajo condiciones de dependencia total de los mayordomos, y tuvieron que dispersarse en diferentes ranchos de la región según las oportunidades que fueron encontrando.

El primer encuentro de casi todos los jóvenes zapatistas con lo que sería por un tiempo su "nuevo hogar" fue decepcionante. Eran ranchos aislados a los que sólo se podía acceder en carro y donde no vivían otros trabajadores. Por ejemplo, cuenta uno de los jóvenes que cuando llegaron era de noche, todo estaba oscuro y en silencio, sólo se oían las chicharras. Cuando el mayordomo les mostró la "traila" en la que iban a vivir pensó que "no era una vivienda digna como por la que estuvo luchando cuando era zapatista". "Estaba sucia, no había letrinas, no había ni un 'pinche' foco, ni agua potable, no había nada, estaba peor que el chiquero de mi cuch". Fue tal la decepción de los recién llegados que una parte del grupo pensó en regresar en ese mismo momento a Lamont. Sin embargo, como estaba oscuro y no conocían el rancho, al final no pudieron emprender la huida. Al día siguiente, muy temprano, llegó el mayordomo para llevarlos a los campos en los que les tocaba trabajar. Su primera experiencia fue en el "amarre de la uva” y, pocos días más tarde, en el espárrago.

Los jóvenes no se quedaron mucho tiempo en el primer rancho. Al entrar en contacto con otros trabajadores que llevaban más tiempo en California, se percataron de que el mayordomo les estaba pagando menos y cobrando mucho por la traila que les rentaba. Además, en el rancho se sentían como "prisioneros" pues, la falta de un vehículo, los obligaba a pasar semanas enteras sin salir del rancho. Muy pronto comenzaron a buscar estrategias para mejorar su situación como explica uno de los jóvenes:

Yo no dilaté mucho con cada patrón, yo me cambiaba, o sea, lo que quería yo era conocer una red de mayordomos y ver dónde pagan mejor, y si aquí no me conviene, pues ya sé que allá me puedo ir. ¿Por qué? Porque si aquí no te pagan bien, te tienes que mover, y yo llegué a ganar 10 dólares la hora gracias a que me estuve moviendo, y ya vieron 
mi trabajo y me pagaban a diez la hora cortando mandarina.

\section{El sistema de subcontratación}

La agricultura californiana depende de un sistema de subcontratación de mano de obra barata, que busca asegurar la disponibilidad de trabajadores a bajo costo durante todo el ciclo agrícola, especialmente en la época de las cosechas. Este sistema está formado por la articulación de dos niveles de intermediación que, juntos, aseguran el funcionamiento de la producción agrícola. En lo alto del sistema se ubican los dueños de las empresas contratistas conocidas como Farm Labor Contractor (FLC) y, en lo bajo, los intermediarios tradicionales, conocidos como mayordomos, quienes muchas veces recurren a su vez a los "enganchadores".

Para analizar cómo funciona este sistema vamos a poner el caso de Pedro, uno de los jóvenes chipanecos quien, en el momento de la investigación en California, estaba trabajando para Juan Gallardo, un mayordomo originario de Guanajuato, con residencia legal, que llevaba varias décadas viviendo en el condado de Kern. Juan Gallardo tiene dos hermanos, uno también es mayordomo y el otro logró convertirse en contratista encabezando una Farm Labor Contractor (FLC). La función principal de estas empresas es retomar una parte de las actividades y las responsabilidades de los agricultores, particularmente, el reclutamiento de mano de obra, la supervisión del trabajo en los campos, el pago de salarios y el control de la fuerza de trabajo. De esta forma, no sólo liberan al agricultor de una parte importante de su carga de trabajo, también le dan la oportunidad de desentenderse de sus obligaciones legales como empleador frente a los trabajadores y frente al Estado.

A lo largo del año, la FLC de la familia Gallardo surte de mano de obra a un promedio de siete agricultores, para lo cual recurre a la ayuda de cinco mayordomos. Su carga de trabajo y sus ganancias dependen de la cantidad de contratos anuales que logra conseguir, ya que el acuerdo con los agricultores es que recibirán "comisiones" sobre cosechas recogidas cuyo monto varía de un cultivo a otro. Como muestran algunos especialistas, estos acuerdos no están enmarcados en un cuadro legal. De hecho, el ochenta por ciento se estos acuerdos son verbales (Villarejo, 1992).

Como sucede en el caso analizado, la mayor parte de estas empresas se encuentra en manos de mexicanos con residencia legal o ciudadanía americana, o de ciudadanos americanos de origen mexicano. Lo anterior se explica por su vínculo con redes migratorias en permanente renovación que les facilitan el reclutamiento de mano de obra, así como el hecho de hablar español, lengua de trabajo en los campos de cultivo. Casi todos los contratistas cuentan con gran experiencia en el trabajo agrícola ya que en el pasado trabajaron como supervisores, mayordomos, capataces, enganchadores o incluso jornaleros. Según los trabajos de Villarejo y Runsten (1993: 30), en California, cada FLC cuenta con un promedio de ocho mayordomos, un supervisor de campo, tres empleados administrativos y alrededor de 280 jornaleros en la temporada alta, siendo frecuente que una parte de los empleados de la empresa sean de la familia del contratista. Aunque ha pasado ya más de una década desde que Villarejo y Runsten hicieron su investigación, esto sigue siendo vigente. Por ejemplo, en el caso del mayordomo Juan Gallardo, el modelo se sigue a la perfección, ya que el hermano mayor tenía una FLC para la que éste y otros miembros de la familia trabajaban. En este caso, la mayor parte de sus jornaleros provenían de Veracruz, Chiapas y Tabasco, es decir, eran los migrantes más recientes. Cuenta uno de los jóvenes que, cada mes, su cheque salía a nombre de la hija de Juan Gallardo y que éste, personalmente, lo cambiaba por efectivo.

Los mayordomos representan el segundo nivel de articulación del sistema de subcontratación californiano. Por lo general, trabajan para alguna empresa contratista, aunque algunos ofrecen sus servicios directos a las granjas. Sus funciones son 
reclutar a los trabajadores, entrenarlos, repartirlos en los campos, asignarles las tareas, supervisar su trabajo, pagarles y todo lo que tenga que ver con la organización del trabajo en los campos de cultivo. Se podría decir que son ellos quienes se encargan de aplicar las políticas laborales de cara a los trabajadores.

Losmayordomos representan un tipodeintermediario que ha sido caracterizado como "tradicional". Al igual que los antiguos "enganchadores" de las plantaciones de caña del periodo colonial, generan relaciones de dependencia con los trabajadores para mantener sujeta la mano de obra (Sánchez, 2001). A diferencia de los contratistas, el mayordomo mantiene una relación personalizada con el trabajador. Esta relación no se limita a una relación laboral o económica. Los mayordomos crean vínculos marcados por prácticas clientelares y paternalistas que les permiten desarrollar mecanismos "informales" de explotación del trabajador, así como un mayor control sobre él.

Por ejemplo, recién llegados, casi todos los jóvenes chiapanecos, tuvieron que pedirle un préstamo a su mayordomo ya que no tenían "ni una cobija para taparse en la noche", "ni ropa para cambiarse", pues sus pocas pertenencias se habían perdido en el desierto. La deuda que contraen en este momento no sólo es económica, es moral, e inaugura el comienzo de una relación de poder en la que el trabajador siempre estará en desventaja. A cambio de este tipo de "favores", los trabajadores son presionados para que le "echen más ganas al trabajo", lo que significa que trabajen más rápido, que acepten salarios bajos, que cumplan con horas extras, que no descansen en tiempo de cosechas, etcétera.

Además de reclutar mano de obra y vigilar su buen funcionamiento en los campos de cultivo, los mayordomos son los proveedores obligados de una serie de servicios básicos sin los cuales los trabajadores no podrían acceder al mercado laboral ni sobrevivir en un medio que les es desconocido (Sánchez, 2001). Por ejemplo, les ofrecen vivienda, transporte y crédito, así como ayuda en distintas situaciones de la vida cotidiana, como el envío de dinero, hablar por teléfono, ir al médico y otros. Estos "servicios" les permiten a los mayordomos obtener mayores ganancias económicas y un mejor control de la fuerza de trabajo, al mismo tiempo que dejan al trabajador en una situación total de dependencia. Como explica un joven:
"A veces el mayordomo es quien consigue la renta, consigue el "raite", a veces, eso lo hacen como para llamar a la gente, como para tenerla ahí a la gente, porque a veces como que no encuentra gente y entonces nos dicen: 'Mira ino tienes renta?, aquí hay renta'. Entonces, así es como ellos 'jalan' a la gente, como que te atrapan".

Otra de las funciones de los mayordomos es disciplinar la fuerza de trabajo, es decir, evitar que haya conflictos en los campos, sobre todo de carácter laboral y, por supuesto, evitar que los trabajadores se organicen o se sindicalicen. Para ello, se sirven de mecanismos informales de control vinculados con las relaciones de "paisanaje", "compadrazgo" o "amistad" que establecen con el trabajador. Por ejemplo, es frecuente que algunos mayordomos ofrezcan a algunos trabajadores "arreglarles sus papeles si le echan ganas" o si los contactan con más trabajadores de su mismo origen. Como cuenta uno de los jóvenes chiapanecos:
Un día me dice ese guey [el mayordomo]: "Oliverio, vente, te traigo una comidita que mi hija preparó, la tortilla también mi hija lo hizo". Y le dije riendo: "Pues no me vendo". "En serio te invito a la casa", me dice, y entonces, cuando fui a su casa, me propuso lo de los papeles, me dice que si quiero pasar a mi familia, que él me da la firma, que como amigos, que si tengo más familiares de Chiapas que vengan a trabajar con él.

En un primer momento Oliverio se ilusionó, pero muy pronto se dio cuenta que era una trampa. Lo que le interesaba al mayordomo era evitar que se sindicalizara 
ya que su ofrecimiento se dio a los pocos días de que los activistas de la Unión visitaran el campo. Además, Oliverio se enteró de que era un mayordomo que acostumbraba "engañar a la gente" y "siempre les quedaba debiendo dinero" a los trabajadores. De hecho, se rumoreaba que de esa forma había logrado comprar varios ranchitos en la región.

\section{4. "En el campo siempre hay prisa"}

Las difíciles condiciones de trabajo en los campos de cultivo de California han sido documentadas desde hace varias décadas por periodistas, investigadores, sindicatos y ONG. La constante descrita puede resumirse en: trabajo pesado, jornadas de más de diez horas, altas temperaturas, exposición a pesticidas, presión para que trabajen rápido, malos tratos, discriminación y bajos salarios. Todo esto se traduce en una vida precaria, accidentes, enfermedades y, a veces, hasta la muerte. Diferentes informes han mostrado que el trabajo agrícola es unas de las ocupaciones más peligrosas en Estados Unidos (Oxfam, 2004). Los jornaleros se exponen a mayores riesgos de lesiones y daños que trabajadores de otras ramas; por ejemplo, el promedio de mortalidad de los trabajadores agrícolas en California es cinco veces más alto que en otras industrias (Ahn, Moore y Parker, 2004).Y esto no es particular de California, sucede lo mismo en Europa, bajo el modelo de agricultura intensiva (véase Décosse, 2008).

El alto riesgo al que se exponen los jornaleros agrícolas tiene menos que ver con la naturaleza de este tipo de actividad que con las condiciones deplorables de trabajo. Muchos accidentes o enfermedades podrían prevenirse si los empleadores acataran los estándares necesarios marcados por la ley y si no presionaran tanto a los jornaleros para que desempeñen rápido su trabajo. Como explica en entrevista un joven zapatista:

En el field siempre hay prisa, los mayordomos nos meten mucha presión y es lo que no quieren los de la Unión. Por ejemplo, en el campo de la uva hay mucha presión, me pasó que me tocaba empacar y, mira, me dijo el mayordomo: "¿Sabes qué?, necesito 45 cajas de uva por cada quien”. En la cuadrilla somos cuatro, 45 cajas cada quien, es lo que tenía yo que empacar. Mis compañeros están en el surco piscando, me traen la uva, me la dejan y yo tengo, en "putiza", que embolsarlo, meterlo a la caja, sellarlo, pesarlo y echarlo a la estiva. Tenía yo que hacer arriba de unas 180 cajas, ese era el promedio que tenía que empacar, pero lo normal era que empacáramos 125.

Esta prisa no sólo tiene que ver con una necesidad inherente a la agricultura (levantar rápido las cosechas para que no se pierdan), más bien responde a la forma en que se organiza la producción. Como me explicó un mayordomo: "A nosotros nos pagan por tonelada recogida". Esto hace que a ellos les interese recoger el mayor número de toneladas en el menor tiempo posible y con el menor número de trabajadores. Esta forma de trabajo se traduce en presión sobre los jornaleros y en el deterioro de sus condiciones de trabajo y de salud. Cada mayordomo tiene su estilo y sus formas para presionar a los trabajadores: "depende del carácter", dice un joven de Veracruz. Los jóvenes chiapanecos tuvieron todo tipo de experiencias. A algunos les decían: "Échenle ganitas muchachos". A otros les gritaban: "Apúrenle 'huevones". La presión que reciben los trabajadores migrantes no sólo viene de los mayordomos. La naturaleza esporádica de su empleo como jornaleros agrícolas constituye una presión extra, pues los obliga a trabajar a un ritmo muy acelerado durante muchas horas diarias. Ellos saben que es la única forma en que lograrán optimizar sus ingresos y compensar los meses que estarán desempleados (Bade, 2004: 236).

Los trabajadores, además, tienen que lidiar con los conflictos que aparecen entre mayordomos, capataces, contratistas y dueños de los ranchos, quienes no siempre tienen los mismos intereses y suelen dar consignas de trabajo distintas a los jornaleros. Como resume un 
joven zapatista apelando a lo aprendido en sus años de militancia en el movimiento: "Ellos mandan pero no saben obedecer". Esa mañana le había tocado trabajar en un viñedo. Mientras sus compañeros de cuadrilla levantaban la cosecha. Este joven escogía, empacaba, pesaba y estivaba las uvas que en unos días estarían comiendo cientos de familias estadounidenses. Normalmente se lograban empacar 80 o 90 cajas por hora ya que era un trabajo muy laborioso. Se trataba de uvas para mesa, que no pueden estar maltratadas. Sin embargo, ese día, el mayordomo les exigió que empacaran 180 cajas por hora y como sabía que era imposible que lo hicieran les dijo a los trabajadores que no escogieran tanto las uvas para que avanzaran más rápido. El problema vino cuando el supervisor se dio cuenta de que había uvas maltratadas en las cajas. Como explica uno de los trabajadores :

Al rato viene otro "cabrón" supervisor, y empieza a checar las cajas y me grita: "Mira, hay unas aguaditas". Por tener una aguadita me tiran toda la "chingada" caja de la estiva. "Lo tienes que rectificar", me dice, y me tiran la caja al piso y me grita: "Rectifica de nuevo". De esa forma, tú lo que haces es que te enojas con ellos porque antes te dijeron otra cosa y entonces empiezas a discutir. Por eso te digo que ellos mandan pero no saben obedecer, así son los patrones aquí (...) Entonces tú te explicas con ellos, pero ellos no te entienden, lo que hacen es que te despiden, te dicen: "Pues mañana ya no vienes".

Los trabajadores se ven así en medio de dos consignas imposibles de satisfacer, pero que los empujan a un ritmo de trabajo superior al de un jornalero local, legal y sindicalizado.

\section{La explotación de los migrantes en los campos californianos}

Durante las dos últimas décadas, el sector agrícola estadounidense ha experimentado un explosivo crecimiento en producción y ventas. En este mismo periodo, la situación de los trabajadores se ha precarizado (Oxfam, 2004). Los jóvenes zapatistas empezaron ganando seis dólares la hora ${ }^{4}$ pero su salario fue variando a lo largo del año, en función de la época productiva, la cantidad de mano de obra disponible en la región, el tipo de cultivo, o si eran contratados por hora o por tarea. ${ }^{5}$ Según cifras de la encuesta NAWS (DOL, 2005), las entradas anuales de los trabajadores agrícolas oscilan entre 10,000 y 12,499 dólares por año, mientras que el promedio de lo que recibe una familia estadounidense oscila entre 15,000 y 17,499 dólares. Otras investigaciones ubican la cifra muy por debajo. ${ }^{6}$ Según lo encontrado durante el trabajo de campo, en los mejores meses, los jóvenes llegaron a ganar 400 dólares a la semana, sin embargo, hubo periodos en los que sólo ganaron 160 dólares. Haciendo una estimación, varios de ellos calculan que sus ingresos anuales no llegaron a 9,000 dólares.

En la época de cosechas los trabajadores migrantes trabajaron de 10 a 12 horas diarias, siete días a la semana, sin recibir el pago de horas extras. Sin embargo, en otras épocas del año, estuvieron desempleados. Por lo general, los trabajadores agrícolas dedican al año un promedio de 34 semanas y media en los campos o granjas (66\%), alrededor de cinco semanas en actividades no agrícolas (10\%) y el resto del tiempo se encuentran desempleados (24\%) (DOL, 2005). El aumento de la duración de la jornada de trabajo y la disminución del valor de la fuerza de trabajo representan piezas clave del sistema de producción californiano. Sin embargo, hay muchos otros mecanismos a través de los cuales, mayordomos, contratistas y patrones, se apropian del trabajo de los jornaleros agrícolas. El siguiente testimonio de un migrante zapatista devela bien algunos mecanismos de explotación de los trabajadores:

La explotación viene desde que el mayordomo te dice: "iÉchenle ganitas muchachos! iÉchenle ganitas porque el espárrago a las 12 se te florea y ya no sirve!". A veces, 
el mayordomo te habla dulce, es igual que un gabacho que te dice "good" y te da una palmadita en la espalda y tú como que te quedas agradecido de que te dijo "good", "mucho gusto", "thank you", "muchas gracias". Como que tú, con esas palabras que te dicen, te sientes agradecido y te vas en "chinga" en el field. Entonces, sin que te des cuenta, ellos lo que quieren es que avancen sus trabajos y, al final de cuentas, aunque tú le eches más ganas, es lo mismo, no te van a pagar más.

Para presionar a los trabajadores, los mayordomos movilizan las deudas morales o económicas que éstos tienen con ellos. También es común que, para aumentar el ritmo de trabajo, pongan a competir a las diferentes cuadrillas utilizando a los recién llegados. Otros mayordomos se aprovechan de las mismas redes de los migrantes para ejercer presión entre sus miembros. Como ya ha sido documentado por Krissman (2002) las propias redes de solidaridad de los migrantes tienen mecanismos de coacción que pueden ser aprovechados por los mayordomos para el control de los trabajadores y para mantener un ritmo elevado de trabajo.

Los mayordomos y contratistas saben que sus ganancias dependen del tiempo de trabajo no remunerado que logren obtener de los jornaleros. Para eso existen diferentes estrategias. Por ejemplo, los cheques de los trabajadores siempre vienen con menos horas de las trabajadas realmente y, cuando el trabajador se atreve a reclamar, los mayordomos justifican estos descuentos diciendo que utilizaron ese tiempo para ir al baño, descansar o cambiarse de campo. Pasa lo mismo cuando son contratados por tarea, pues los mayordomos no reportan lo que realmente realizó cada trabajador.

También es usual que los mayordomos paguen con retraso o que, al final de la cosecha, les queden a deber varias semanas de salario a los jornaleros. Según la ley de California, los mayordomos tienen que pagar semanalmente pero algunos estilan pagar con varias semanas de atraso. Esto les permite mantener cautiva la mano de obra inmigrante, lo que es provechoso cuando ésta escasea. Otros acostumbran a quedarse con parte de los salarios de los trabajadores, sobre todo si se trata de indocumentados recién llegados, pues difícilmente tendrán manera de exigir lo que les corresponde.

\section{El encuentro con la Unión}

En un contexto como el descrito hasta este momento resulta muy difícil para los migrantes recién llegados, incluso para los migrantes zapatistas, organizarse políticamente para la defensa de sus derechos humanos y laborales. Como ya ha sido demostrado por algunos especialistas, los migrantes indocumentados, más que cualquier otro grupo al interior de la sociedad, enfrentan grandes obstáculos para la organización colectiva y su expresión en el espacio público (De Lucas, 2004: 23; Fassin y Morice, 2001). Entre estos obstáculos cabe destacar la falta de reconocimiento jurídico, es decir, no tener papeles, y una situación económica precaria. A pesar de estas dificultades algunos de los migrantes zapatistas entraron en contacto rápidamente con los sindicatos de la región. Como cuenta uno de ellos:

Apenas llevaba una semana trabajando en un rancho del "Indio" y llegó una muchacha con su gafete y su libreta en la mano y entonces nos preguntó: "Muchachos icon quién trabajan?". "Pues con la familia Gallardo". "¿Cómo los han tratado?" "Pues hasta ahorita me han tratado bien". "iY les paga?". "Si, nos han pagado bien, hasta ahorita no tenemos problema, nos ayudó y todo". "Está bien" dijo, "yo no estoy en contra, pero si no les pagan o les quedan mal, o algún maltrato, estoy para servirles, estoy para ayudarlos”. iUn contacto más! Eran los de la Unión de César Chávez.

En este primer encuentro la sindicalista les habló de sus derechos como trabajadores, les entregó propaganda del sindicato y les invitó a participar en sus reuniones. A diferencia de lo que sucede con otros trabajadores, para 
los jóvenes zapatistas, el discurso de los sindicalistas no era algo ajeno. Por el contrario, lo entendían, por lo que aceptaron participar. En sus años de militancia en el zapatismo todos ellos aprendieron lo importante que es conocer sus derechos, pues saben que esa información será un recurso valioso para desenvolverse en el nuevo contexto: "Yo estaba interesado en saber mis derechos, o sea, saber, entender, pues, que no te engañen" me explica uno de ellos

Los jóvenes asistieron a varias reuniones de la Unión. Ahí aprendieron que, aunque no tuvieran papeles, los patronos están obligados a proporcionarles las condiciones adecuadas para desarrollar su trabajo: baños, agua potable, vasos, agua para lavarse, sombra, etcétera. Deben procurarles gratuitamente las herramientas, darles un descanso de 10 minutos por cada 4 horas y 30 minutos para comer. Si se enferman o se lastiman en el trabajo, el patrón está obligado a darles servicio médico y una compensación si pierden más de tres días. No pueden pagarles menos del salario mínimo por hora establecido para California y, después de la octava hora de trabajo, deben pagarles tiempo y medio. Como explica uno de ellos: "Así es como fui recogiendo información y fui conociendo, me fui metiendo".

Después de las reuniones en Arvin, los sindicalistas invitaron a los jóvenes a un evento regional que tuvo lugar en la ciudad de Bakersfield. En esta ocasión sólo uno de ellos se animó ya que, para los otros, implicaba perder un día de trabajo y tener problemas con sus mayordomos. El joven que aceptó dice que lo hizo porque necesitaba ayuda del sindicato para enviar dinero a su familia. Es frecuente que los primeros contactos entre los trabajadores indocumentados y los sindicatos se basen en un interés mutuo de distinto orden: mientras los trabajadores se apoyan en el sindicato para resolver cuestiones muy concretas que se les presentan en su vida cotidiana, los sindicatos buscan construir una base social activa.

En varias ocasiones los sindicalistas de la Unión regresaron al rancho a buscar a los jóvenes zapatistas.
Querían convencerlos de que se volvieran activistas de la Unión y los ayudaran a organizar a otros trabajadores. Para la Unión resultaba difícil organizar a los migrantes recién llegados y en permanente movimiento. Sin embargo, ningún joven aceptó: "Ahorita no es tiempo de que yo me dedique a la lucha, tengo que ver por mi familia, porque para eso vine, pero después pienso que sí me va a gustar participar, porque yo ya vi todo lo que se sufre en el field, ya vi hasta morir a un trabajador". El rechazo a participar en la Unión no significa que no les interese hacer valer sus derechos, lo que sucede es que, en ese momento, la mayor preocupación de los jóvenes era sobrevivir en el nuevo contexto, trabajar para poder pagar su deuda y cumplir sus proyectos migratorios. No hay que olvidar que, al momento de la investigación, llevaban menos de un año en Estados Unidos y que fueron los primeros de su pueblo en emigrar, por lo que no contaban con apoyo familiar. Los primeros años de migración, los jóvenes se enfocan en estabilizar su situación económica, comprender el funcionamiento del sistema, construir una red migratoria, etcétera.

\section{La vida cotidiana y el consumo de alcohol}

La vida diaria en Arvin "pues es pensar en el trabajo, pensar en el trabajo y, si te gusta tomar, pues tomar, ino hay más!". Así resume su vida cotidiana un joven zapatista que llevaba dos años viviendo en Estados Unidos. En época de trabajo los jornaleros pasan la mayor parte del día en los campos y, por la tarde, vuelven a sus cuartos en los patios traseros de sus mayordomos. Ahí preparan la comida, lavan ropa, se bañan, hablan por teléfono y se alistan para madrugar al día siguiente. Su vida transcurre entre los campos y sus pequeñas viviendas ya que, además de temer a una eventual deportación, tienen miedo de la policía y las pandillas del barrio, quienes muchas veces los asaltan. Para los trabajadores que viven en los ranchos la exclusión de los espacios sociales es aún más marcada 
pues se encuentran lejos de los centros urbanos y de los otros trabajadores.

Así, los primeros meses después de cruzar la frontera están marcados por un fuerte sentimiento de miedo y vulnerabilidad, vinculado sobre todo con su nueva situación como migrantes irregulares. Al establecerse en Estados Unidos sin contar con un permiso de residencia, los migrantes son categorizados jurídicamente como "ilegales" y estigmatizados socialmente como personas "fuera de la ley". Lo anterior tiene profundas consecuencias sobre la forma en que se va a estructurar su vida cotidiana y sobre cómo se va a construir su nueva identidad.

La vida cotidiana de los trabajadores transcurre en estrecha convivencia con otros jóvenes jornaleros, pero mantienen muy pocos contactos con personas externas al medio. Cada joven pertenece a una "cuadrilla", es decir, forman pequeñas unidades de producción, constituidas por tres o hasta seis trabajadores, a partir de las cuales se organiza el trabajo en los campos de cultivo. Las cuadrillas, además de tener una función económica central en la vida de los migrantes, cumplen numerosas funciones sociales y afectivas pues para muchos trabajadores, son el núcleo primario de su socialización en el Norte. Como ellos mismos dicen: "Mi cuadrilla es, haga de cuenta, como mi familia, aunque no seamos nada". Efectivamente, la cuadrilla se convierte en el hogar de muchos migrantes. Un hogar muy poco convencional ya que está formadoúnicamente por hombres entre los que no existe necesariamente un vínculo consanguíneo y, muchas veces ni siquiera provienen de la misma región. En estos grupos se crean fuertes lazos de afecto y solidaridad ya que, además de compartir el mismo techo y los gastos comunes de la casa, tienen sueños y objetivos migratorios muy parecidos y se enfrentan a los mismos problemas. Las cuadrillas no son grupos estáticos e inamovibles, por el contrario, es frecuente que sus miembros cambien cada cierto tiempo ya que en la región hay una permanente circulación de trabajadores.
Los miembros de la cuadrilla mantienen un alto nivel de convivencia. No sólo trabajan juntos en los campos, conviven durante el resto de sus actividades cotidianas. Por ejemplo: van al supermercado, envían dinero, hablan por teléfono, van al médico, celebran sus eventos, etcétera. El funcionamiento en cuadrillas mitiga algunos efectos de la exclusión y les permite a los trabajadores tener una vida social. Además, algunas cuadrillas desarrollan estrategias colectivas para mejorar su situación en el trabajo. Por ejemplo, se compran una camioneta para transportarse a los campos y no tener que pagarle diariamente una parte de su salario al mayordomo. Como explica un joven zapatista: "Nos vendían una 'troca' viejita en 1500 y pues nos pusimos de acuerdo todos los de la cuadrilla y le entramos". Al agruparse para comprar la camioneta, el costo y los gastos de manutención se reducen considerablemente.

El alcohol tiene un lugar central en la vida de muchos migrantes pues, al no tener acceso a otro tipo de espacios recreativos, su único "entretenimiento" a la mano es beber. El consumo de alcohol ha tenido consecuencias importantes en la vida cotidiana de los jóvenes. Por ejemplo, la incapacidad para ahorrar o mandar remesas a sus familias, el endeudamiento, la pérdida del empleo, los accidentes automovilísticos y el encarcelamiento por incidentes en estado de ebriedad.

Para no estigmatizar a los migrantes por el consumo de alcohol quiero enfatizar que esta práctica no debe interpretarse como un problema ligado a su personalidad ni como una cuestión exclusiva del orden privado. Es un problema que tiene que ver con el sufrimiento o malestar ocasionado por su ilegalización y la ausencia de espacios de reconocimiento en la sociedad de arribo. Si interpretamos este hecho con ayuda de la teoría de Axel Honneth (2000) sobre el no reconocimiento, podemos decir que el consumo de alcohol les ayuda a los jóvenes migrantes a soportar las "heridas morales" producidas por esta situación. Como explican Lazzeri y Caillé (2004: 104) en su lectura de Honneth y Renault, una "herida moral" no es otra 
cosa que un sufrimiento particular que manifiesta la vulnerabilidad de un individuo (o de un grupo social) de cara a una serie de depreciaciones de las que es (o son) objeto, ya sea que tomen la forma de una simple indiferencia o que se encuentren revestidas de un "desprecio social".

En el contexto migratorio, el consumo colectivo de alcohol es también una forma de reforzar el lazo social con otros compañeros de interacción, de verse insertos en un grupo de solidaridad en el que se mantienen relaciones de camaradería. Para los jóvenes migrantes "beber juntos" es una forma de afirmar públicamente esta camaradería, de afirmar la estima mutua. "Nos gusta tomar entre amigos, así no más, para convivir, para estar alegres un rato". Alrededor de la bebida los jóvenes construyen un espacio de convivencia y de muto reconocimiento en el que obtienen la confianza y la estima que la sociedad de arribo no les brinda: "Yo tomo porque así trato la manera de satisfacer sus convivencias, para no salir de la armonía que tienen ellos en pistear", dice uno de ellos. En un contexto en el que el único reconocimiento al que pueden acceder es al de sus pares de interacción, los jóvenes migrantes se ven orillados a ser partícipes de una forma de socialización mediada por el consumo de alcohol, de lo contrario, pierden el único espacio para una socialización horizontal. Como cuenta un joven:

Aquí siempre hay alguien que te dice "Tómate una cerveza", y pues ni modo de decirles no. Tienes que agarrar la cerveza y de esa forma se quedan ellos satisfechos y luego ya se van, ellos siguen su ruta y yo sigo mi ruta. Eso es lo que yo hago para que al rato no digan "Ese cabrón se siente mucho", yo así trato la manera de no ofenderlos, de convivir con ellos, en una manera así tranquila, pacífica. Porque si no aceptas la cerveza, icómo te dijera?, después hablan de ti o ya te miran con malas caras, se enojan contigo; en fin, hay algo así entre la familiarización del amigo, de la red. O sea, ya queda uno fuera de la red.

\section{La "fuga" de la agricultura}

Al alargar la jornada de trabajo, la producción capitalista no sólo conduce al empobrecimiento de la fuerza humana de trabajo (...) produce además la extenuación y la muerte prematura de la misma fuerza (...) se alarga el tiempo de producción del obrero durante cierto plazo a costa de acortar la duración de su vida (Marx, K., El Capital. México: FCE, 1972, p. 208, (capítulo VIII La Jornada de Trabajo).

Los jóvenes chiapanecos son normalmente contratados para los trabajos de cosecha (cortey pizca) y pre-cosecha (trabajo con azadón, desahíje de frutas y hortalizas, limpieza, instalación de plástico, amarre y transplante), considerados los más duros y desgastantes. De ahí que, después de unos cuantos meses en este sector, se dieran cuenta de que no era un trabajo sostenible a largo plazo. Como explica uno de ellos: "Pensé que si me quedaba mucho tiempo trabajando en el 'field' me iba a acabar totalmente, es mucha 'chinga', por eso busqué la manera de salirme”. En el mismo sentido, otro joven comenta: "En el campo te explotan un 'chingo', por eso yo me puse a pensar ¿cuántos años voy a poder aguantar? No creo que ni llegue a cuatro y eso que estoy acostumbrado al trabajo en el campo". Después de algunos meses de trabajo, una minoría logró que sus mayordomos los incorporaran a actividades semicualificadas (podar, regar, rociar y el mantenimiento de huertas), así como al empaque de los productos. Sin embargo, los mayordomos tienen mucha resistencia para sacarlos del field. Saben que son una mano de obra calificada para las labores agrícolas pues siempre han sido campesinos, lo que ya no es tan fácil encontrar. Así, al ver las pocas oportunidades que tendrían en este nicho laboral para una movilidad ascendente o, como dicen ellos, para "salir adelante", gran parte de los jóvenes zapatistas decidió "escapar" de la agricultura. Esta situación contrasta con lo que ha pasado con otros grupos que se han quedado años o hasta décadas 
trabajando en los campos. Por ejemplo, en las cuadrillas de los chiapanecos había jóvenes de diferentes orígenes que llevaban mucho más tiempo que ellos en los campos y que, sin embargo, no tenían la intención de moverse. Como explica uno de los migrantes chiapanecos:

Entonces con el tiempo vas conociendo y te superas, porque yo te digo que yo estuve trabajando con mayordomo y con contratista, y se admiran algunos amigos porque ellos tienen tres, cuatro años aquí y se admiran de que cómo le hizo uno, cómo le hace uno, porque ellos siguen en el campo, tú estás en una fábrica, ellos siguen en el campo, tú estás en un empaque, estás dentro de una casa, dentro de una tienda, vas conociendo, vas desarrollando tu mente, vas tejiendo la red, vas filtrándote y filtrándote, y conforme vas saliendo, vas filtrándote, tu mente va desarrollando, vas pensando: imejor yo me voy pa'cá!

La salida de la agricultura representa lo que MoulierBoutang ha llamado la "fuga" para liberarse del control que el Estado ejerce sobre la movilidad de los trabajadores, gracias a las políticas migratorias mediante las que los "ilegalizan". Salir de este mercado de trabajo no es fácil. Todo está estructurado para que los jóvenes se queden "encerrados afuera", en estos campos de relegación (véase Kobelinsky y Makareni, 2009) y explotación. El hecho de que los jóvenes no tengan papeles les impide desplazarse libremente por la región para buscar otros empleos. Además, como explica De Genova (2004: 206), "la producción legal de la ilegalidad proporciona un dispositivo que sirve para reforzar la vulnerabilidad y la maleabilidad de los inmigrantes mexicanos -en tanto trabajadores-cuya fuerza de trabajo, justamente gracias a que es expulsable, se vuelve una mercancía altamente disponible". Así, al ser potencialmente "deportables", los migrantes zapatistas viven con un miedo permanente que les dificulta desenvolverse y desarrollar sus potencialidades en el nuevo contexto.
Como explica uno de los migrantes chiapanecos: "Ser ilegal es como traer una piedrita en el zapato que siempre te está molestando y no te deja avanzar". Además de que ser ilegales los expone altamente a la explotación y a situaciones de abuso.

En el caso de la agricultura californiana es muy claro cómo el control geográfico de la movilidad de los migrantes indocumentados tiene por objeto evitar también su movilidad social hacia mercados de trabajo tomados por los ciudadanos estadounidenses (Moulier-Boutang, Garson y Silberman, 1986: 86-87). No es casualidad que la Migra ejerza un estricto control sobre una extensión de 25 millas alrededor de la zona agrícola, como si buscara contener a los migrantes indocumentados dentro de ciertas zonas agrícolas, y prohibirles el acceso a las carreteras hacia Detroit o la costa este donde, eventualmente, podrían incorporarse en otro tipo de empleos (Martin cit. en MoulierBoutang, Garson y Silberman, 1986).

Una forma privilegiada para impedir su movilidad es la confiscación de sus automóviles. En las entrevistas de los jóvenes es recurrente que hablen de los múltiples incidentes que han tenido con la policía mientras conducían sus carros. Las carreteras de todos los condados del valle de California están muy bien vigiladas y es muy peligroso circular por ahí. Lo curioso, según los jóvenes es que, la mayor parte de las veces, sólo les confiscan sus carros pero no llaman a la Migra para su deportación, particularmente si se encuentran en tiempos de cosechas. Como cuenta un muchacho:

Fue una locura lo que hicimos de comprar carros y que luego nos los quitaba la "placa" (policía). Un día íbamos para Sacramento a cobrar un cheque y la "placa" nos quita nuestra Minivan. Entonces compramos una Ven chica y a los pocos días que nos vuelven a "mochar" el carro. Quedamos de nuevo sin carro y volvimos a trabajar y, cuando juntamos, que volvemos a comprar otro carrito. iEs poco si te digo que la "placa" me paró siete veces! 
Esta situación se encuentra estrechamente vinculada con la doble intencionalidad de una "política de control", cuyo objetivo explícito es impedir la presencia de trabajadores indocumentados, mientras su objetivo oculto es mantener esta fuerza de trabajo en una inferioridad jurídica que permita precarizar el mercado de trabajo (Moulier-Boutang, Garson y Silberman, 1986: 87).

Cuando sus carros son confiscados, los jóvenes ya no pueden trasladarse a los diferentes ranchos y muchas veces o vuelven a contratar los servicios de sus mayordomos o vuelven a comprar otra camioneta. Cuando esto último sucede es frecuente que los jóvenes caigan en un círculo vicioso en el que invierten todo su dinero en la compra de camionetas viejas y muy pronto las pierden en un nuevo incidente con la policía. Esto provoca que los jóvenes pasen meses sin enviar remesas a sus hogares y que no tengan capacidad de ahorro para aguantar los meses de invierno.

\section{El viaje hacia Mississippi}

Los jóvenes zapatistas recorrieron decenas de ranchos de la región. En todos encontraron más o menos las mismas condiciones de trabajo: salarios bajos, ningún derecho laboral, jornadas de trabajo de más de ocho horas, altas temperaturas en los campos, presión de los mayordomos para trabajar rápido, alto riesgo de accidentes de trabajo, exposición a pesticidas, etcétera. Ante este panorama, y por las pocas posibilidades que tenían de cambiar de sector, los migrantes chiapanecos decidieron atravesar el país en dirección a los estados de la costa este.

Anduve por Sacramento, Reucity, Palo Alto y en los ranchitos de San Francisco, Entonces, mientras conocía y trabajábamos, íbamos planeando nuevamente para dónde salir, para dónde ir, si nos quedábamos ahí o salíamos a otro lado, tratar de conseguir trabajo en otra parte, porque lo que comentábamos es que, si seguimos en el campo, no vamos a hacer nada, en el campo no aguantamos más de dos años o un año o unos meses no más, porque en el campo es más maltratado, más asoleado, más duro, más difícil, más te explotan.

El destino que tenían en mente los jóvenes zapatistas era Biloxi, Mississippi. Luego del paso del huracán Katrina en 2005 un grupo cada vez más grande de jóvenes de esa región se habían instalado en esa ciudad. El problema era, ¿cómo cruzar casi 3000 kilómetros y siete estados sin ser detenidos por la policía? Las opciones no eran muchas: pagar un "pollero" que les cobraría 1500 dólares por persona o comprar una camioneta y lanzarse solos a la aventura. Todos prefirieron la segunda opción ya que, el año anterior, varios grupos de jóvenes habían salido de la misma forma, rumbo al estado de Alabama.

Entonces ya decidimos y nos pusimos de acuerdo en que vamos a comprar otra "troca" para podernos mover; así que dijimos que el cheque que salga esta semana va para eso. Total que, al final, éramos siete y pudimos sacar una Explorer. Dicen que preguntando se llega hasta Roma y así le vamos a hacer nosotros. Entonces compramos un mapa y, además, vamos a tener comunicación de aquí para allá y, como ellos ya saben más o menos el camino, pues nos van a ir diciendo para dónde hay que agarrar. Salimos ese día y, como a las tres horas, que vemos la "pinche" humazo de la "troca". Íbamos subiendo al sierra, ya no había ciudad y empieza a salir humo y humo y pensamos que va arder la "troca", pero no, rápido le limpiamos el aceite que había caído y ya seguimos el viaje.

Tardaron cuatro días y cuatro noches en llegar a Mississippi. No se detuvieron más que para echarle gasolina a la camioneta. El grupo iba bien organizado: los que sabían manejar eran choferes y el resto copilotos, Luego hicieron turnos para rotarse cada cierto tiempo. Pese al gran riesgo que implicó este 
viaje, los jóvenes lo recuerdan como una experiencia muy alegre: "Veníamos platicando, riéndonos, con el relajo, porque ya sabes que los de María Trinidad somos bien relajistas". El viaje se desarrolló sin ningún imprevisto y, salvo algunas confusiones al momento de cambiar de carretera, todo les salió bien y llegaron a su destino.

Una vez en la costa este del país, los migrantes zapatistas comenzaron un periodo de dispersión y de mucha movilidad, siempre en busca de mejores sitios de trabajo y lugares más favorables para establecerse: Alabama, Mississippi, Louisiana, Florida, Carolina del Norte, Carolina del Sur, Virginia, Virginia Occidental, Tennessee, Ohio, Pennsylvania, Georgia y Nueva York, serán algunos de los estados por donde transitarán estos jóvenes. En este largo errar, enfrentarán siempre condiciones laborales inestables y fragmentarias que no les permitirán quedarse por mucho tiempo en el mismo lugar.

\section{Conclusiones}

En este artículo se trató de mostrar cómo, si bien los migrantes zapatistas se insertan en el mercado de trabajo californiano con relativa facilidad, lo hacen en condiciones de extrema precariedad y de dependencia casi total de los mayordomos y otros intermediarios. Además, frecuentemente, su inserción significa separarse, a veces por meses, del grupo de jóvenes con el que cruzaron la frontera. Por su condición de migrantes irregulares, estos jornaleros agrícolas de reciente arribo, representan el tipo ideal de "salariat bridê" (asalariado cautivo) (Moulier-Boutang, 1998), sin libertad de circulación, sin acceso a la ciudadanía y en condiciones de trabajo deplorables. Su experiencia nos permite observar la forma en que opera un sistema de control de mano de obra migrante basado, por un lado, en la "inferiorización jurídica" (Moulier-Boutang, 1998) - o como diría De Genova (2004) en la producción de su "ilegalidad"-y, por otro, en la utilización de un sistema de subcontratación de mano de obra que, al combinar mecanismos modernos y tradicionales de enganche (cuya pieza clave es la figura del intermediario), permite la disponibilidad de trabajadores bien disciplinados a bajo costo durante todo el año.

Si bien el sistema de control de la movilidad de los jornaleros agrícolas deja poco espacio para su autonomía personal y para la emergencia de una acción colectiva contestaría, los migrantes zapatistas han tratado de modificar esta situación, por ejemplo, algunos se han acercado temporalmente a sindicatos u otras organizaciones. El problema es que, a pesar de ser trabajadores receptivos a estas formas de acción colectiva y al discurso de los derechos, en esta etapa de su experiencia migratoria, no les es posible establecer un compromiso político a largo plazo pues están demasiado exigidos tratando de sobrevivir. De ahí que la mayor parte de los jóvenes zapatistas hayan optado mejor por la "fuga" de los campos. Es decir, han tratado de moverse hacia otras regiones y otros mercados de trabajo, donde no se expongan a una situación de explotación tan extrema como en la agricultura ya que su trabajo en los campos no sólo conduce a la precarización de su vida, sino que pone en peligro sus propios cuerpos. Las "fugas" se han dado en condiciones de mucha fragilidad y no siempre se han realizado con éxito ya que para los nuevos migrantes es casi imposible insertarse en nuevos mercados de trabajo, saturados por migrantes de más larga data y por los propios ciudadanos estadounidenses. Además, no es fácil salir físicamente de esos campos de cultivo y confinamiento transitados en todas sus arterias por una policía que aprovecha cualquier mínimo incidente para detener a los migrantes, aunque sorprendentemente, la mayor parte de las veces, no los deportan, sólo les decomisan los vehículos que les permitirían concretar su "fuga". A pesar de todo muchos migrantes zapatistas han logrado salir de la agricultura y se han insertado en nuevos mercados de trabajo. 


\section{Notas}

${ }^{1}$ Según datos de la encuesta NAWS de 2005, 75\% de los trabajadores agrícolas nacieron en México, 23\% en Estados Unidos y 2\% en América Central. De aquellos que nacieron en Estados Unidos, casi todos son de origen mexicano (DOL, 2005). Según esta misma encuesta 50\% del total de los trabajadores agrícolas no tiene permiso de trabajo (DOL, 2005).

2 Desde hace algunas décadas también han llegado trabajadores migrantes de origen triqui de Oaxaca, quienes se han insertado en lo más bajo de esta jerarquía (véase Holmes, 2006 y Paris, 2008).

${ }^{3}$ El artículo es una versión resumida de un capítulo de mi tesis doctoral, sustentada en 2010. Toda la información aquí presentada proviene del trabajo de campo que realicé entre 2005 y 2007 en tres diferentes puntos: una comunidad zapatista del municipio de Las Margaritas, la localidad de Arvin en el condado de Kern, California, y la ciudad de Biloxi, en Mississippi. La estrategia metodológica fue la etnografía multi-local, es decir, intenté seguir a este grupo de jóvenes en sus trayectos y estancias entre Chiapas, California y Mississippi. Sin embargo, lo que voy a presentar en estas páginas corresponde centralmente a la estancia en California. Se trató básicamente de una investigación etnográfica, aunque realicé también alrededor de 50 entrevistas en profundidad con jóvenes zapatistas, con sus familiares y con los migrantes con los que vivían o formaban parte de sus cuadrillas de trabajo. Todas las entrevistas fueron realizadas por la autora en 2005 y 2006, en California y Mississippi.

${ }^{4}$ El sueldo mínimo en California era entonces $\$ 6.25$ por hora (información tomada de la pagina electrónica de la California Rural Legal Asístanse).

${ }^{5}$ Por ejemplo: en el amarre de la uva pagan siete centavos por viña, por lo que para sacar 10 dólares, el trabajador tiene que hacer más de 100 matas (entrevistas a trabajadores, octubre 2005).
${ }^{6}$ El California Institute for Rural Studies (Villarejo, Lighthall, Williams y otros, 2000) señala que el ingreso promedio de los trabajadores va de 7500 a 9900 dólares anuales; por su parte, Palerm (1991: 7) ubica esta cifra en 7992 dólares.

\section{Bibliografía}

Aquino, Alejandra (2009), "Entre el sueño zapatista y el sueño americano: la migración a Estados Unidos vista desde las comunidades zapatistas", en Migración y Desarrollo, núm. 13, pp. 79-95.

Ahn, Christine, Moore, Melissa y Parker, Nick (2004), "Migrant Farmworkers: America's New Platation Workers", en Backgrounder, vol. 10, núm. 2, pp 1.5.

Bade, Bonnie (2004), "Aquí estamos: trabajo agrícola, enfermedad y alternativas a la biomedicina entre las familias mixtecas migrantes en California”, en: Jonathan Fox y Gaspar Rivera-Salgado (coords.), Indígenas mexicanos migrantes en los Estados Unidos, México: LIX Legislatura / Universidad de California Sta. Cruz / Universidad Autónoma de Zacatecas / Miguel Ángel Porrúa, pp. 231-275.

Berlan, Jean-Pierre (1986), "Agriculture et migrations", en Revue Européenne des Migrations Internationales, vol. 2, núm. 3, pp. 9-32.

California Departament of Food and Agriculture (CDFA) (2006), "California Agriculture. Highlights 2006”. www.cdfa.ca.gov/card/pdfs/ AgHighlightsBrochure06.pdf [29 de mayo 2010]

Castro, Gustavo (2005), "Las remesas de los migrantes. La migración en Chiapas II”, en Chiapas al Día, núm. 480, pp. 1-7.

Décosse, Frédéric (2008), "La santé des travailleurs agricoles migrants: un objet politique?" Études Rurales, núm. 182, vol. 2, pp. 103-120.

De Genova, Nicholas (2004), "The legal production of mexican/migrant 'illegality”'. en Latinos Studies, vol. 2, pp. 160-185. 
De Lucas, Javier (2004), "La inmigración como res política", en Cuadernos Electrónicos de Filosofía del Derecho, no. 10, pp. 1-44.

Department of Labor (DOL) (2005), "Findings from the National Agricultural Workers Survey (NAWS) 2001-2002", en Research Report, núm. 9, en www.doleta. gov/agworker/report9/naws_rpt9.pdf [7 de mayo 2011].

Durand, Jorge y Massey, Douglas (2003), Clandestinos. Migración México-Estados Unidos en los albores del siglo XXI, México: Miguel Ángel Porrúa / Universidad Autónoma de Zacatecas.

Fassin, Didier y Morice, Alain (2001), "Les épreuves de l'irrégularité: les sans papiers, entre deni d'éxistence et reconquete d'un status", en Dominique Schanapper (edit.), Exclusions au coour de la Cité, pp. 261-309. Paris: Economica.

Granovetter, Mark (2000), "La fuerza de los vínculos débiles”, en Política y Sociedad, núm. 33, pp. 41-56.

Harvey, David (1998), La condición de la posmodernidad. Investigaciones sobre los orígenes del cambio cultural. Buenos Aires: Amorrortu Editores.

Holmes, Seth (2006), "Parce qu'ils sont plus prés du sol. L'invisibilisation de la souffrance sociale des cueilleurs de baies", en Actes de la Rechercher en Sciences Sociales, núm. 165, pp. 28-5l.

Honneth, Axel (2000), La lutte pour la reconnaissance. París: Le Cerf.

Jáuregui, Alfredo y Ávila, María de Jesús (2007), "Estados Unidos, lugar de destino para los migrantes chiapanecos", en Migraciones Internacionales, vol. 4. núm. 1, pp. 5-38.

Krissman, Fred (2002), “Apples and Orange?: recruiting indigenous Mexicans to divide farm labor markets in the western US", presented at Indigenous Mexican Migrants in the US: Building Bridges between Researchers and Community Leaders, october 11-12, Santa Cruz, California.

Kobelinsky, Carolina y Makaremi, Chowra (coords.) (2009), Enfermés dehors. Enquêtes sur le confinement des étrangers, Paris: Editions du Croquant, Terra.
Lazzeri, Christian y Caillé, Alain (2004), "La reconnaissance aujourd'hui. Enjeux théoriques, éthiques et politiques du concept". En: Revue du M.A.U.S.S., núm. 23, pp.88-115.

Matonti, Frédérique y Poupeau, Franck (2004), "Le capital militant. Essai de définition", en: Actes de la Recherche en Sciences Sociales, núm. 155, pp. 4-11.

Moulier-Boutang, Yann (1998), De l'esclavage au salariat. Économie historique du salariat Bride. Paris: Presses Universitaires de France.

Moulier-Boutang, Yann, Garson Jean-Pierre y Silberman, Roxane (1986), Économie politique des migrations clandestines de main-d'ouvre: comparaisons internationales et exemple français. Paris: Publisud.

Nagengast, Carol y Kearney Michael (1990), "Mixtec Ethnicity: Social Identity, Political Consciousness and Political Activism". En: Latin American Research Review, vol. XXV, núm. 2, pp. 61-91.

Oxfam America (2004), "Like Machines in the Fields: workers Without Rights in American Agriculture". www.oxfamamerica.org, [consultado: 29 de mayo de 2010].

Paris, M. Dolores (2008), "Estratificación laboral, migración transnacional y etnicidad", en Laura Velasco, coord., Migración, fronteras e identidades étnicas transnacionales. México: Colegio de la Frontera Norte / Miguel Ángel Porrúa, pp. 239-266.

Palerm, Juan (1991), Farm labor needs and farm workers in California 1970 to 1989, Santa Bárbara, California: Employment Development Departament.

Pickard, Miguel (2006), "La migración vista desde Chiapas", Chiapas al Día, núm. 519, pp. 1-8.

Rus, Dianey Rus, Jan (2008), "La migración de trabajadores indígenas de Los Altos de Chiapas en Estados Unidos, 2001-2005: el caso de San Juan Chamula", en Daniel Villafuerte y María del Carmen García, Migraciones en el sur de México y Centroamérica. México: UNICACH/ Miguel Ángel Porrúa, pp. 343-382.

Sánchez, Kim (2001), "Acerca de enganchadores, cabos, capitanes y otros agentes de intermediación 
laboral", en Estudios Agrarios, Nueva Época, año 7, núm. 17, pp. 61-103.

Villafuerte, Daniel y García, María del Carmen (2006), "Crisis rural y migraciones en Chiapas", en Migración y Desarrollo, núm. 6, pp. 102-130.

Villarejo, Don, Lighthall, David, Williams, Daniel y otros (2000), "Sufriendo en Silencio: Un reporte acerca de la salud de los trabajadores agrícolas de California”, en California Institute for Rural Studies. www.cirsinc. org/docs/Sufriendo_en_Silencio.pdf, [consultado: 29 de mayo de 2010].

Zabin, Carol, Kearney, Michael, Runsten, Dave y otros (1993), Mixtec Migrants in California Agricultura: A New Cycle of Poverty. Davis, California: Institute for Rural Studies. 